\title{
IMPACT OF ALENDRONATE GEL ON BONE DENSITY IN IMMEDIATELY LOADED DENTAL IMPLANTS: A CLINICAL STUDY
}

\author{
Eman Abdel Salam Yousef* and Islam Mohammed Ateia**
}

\begin{abstract}
Purpose: Scientific researches have focused attention on accelerating osseointegration around dental implants to increase their success rate. Accordingly, many materials and techniques have been developed to optimize bone remodeling especially in immediately loaded implants. This clinical study aimed to investigate the impact of topical application of alendronate gel $1 \%$ on bone density around immediately loaded dental implants.
\end{abstract}

Materials and Methods: Twenty dental implants were inserted in 16 patients. Cases were divided randomly into two equal groups; Group I (study group): 10 implants were placed after injection of alendronate gel $1 \%$ in the drilling sites. Group II (control group): 10 implants were placed immediately after drilling; no material was applied to their osteotomy sites. All implants were loaded immediately within 24-72 hours. In each implant recipient sit, bone density was determined pre-operatively using cone-beam computerized tomography (CBCT), then re-evaluated after six months of implant placement and loading.

Results: The mean bone density pre-operatively for Group I and Group II were 557.30 \pm 132.06 $\mathrm{HU}$ and $567.62 \pm 110.72 \mathrm{HU}$ respectively. After six months, the corresponding values were $852.03 \pm 176.43 \mathrm{HU}$ and $670.11 \pm 117.71 \mathrm{HU}$ respectively, indicating a statistically significant difference in bone density $(\mathrm{P}=0.014)$ between both groups.

Conclusion: Topical application of sodium alendronate gel increases bone density around dental implants, which can increase success rate of immediately loaded implants.

Keywords: Alendronate gel, bone density, immediately loaded implants, CBCT.

* Assistant Professor of Oral Surgery, Department of Oral \& Maxillofacial Surgery, Faculty of Dentistry, Mansoura University

** Assistant Professor of Oral Medicine and Periodontology. Department of Oral Medicine and Periodontology, Faculty of Dentistry, Mansoura University 


\section{INTRODUCTION}

Over the last few decades, the demand for replacement of a non-restorable or a missing tooth by a dental implant has increased. ${ }^{(1)}$ In healthy patients, the success rates of osseointegrated dental implants have ranged between 90\%-95\%. However, about $10 \%$ failures are still recorded, which can be attributed to the poor quantity and/or quality of bone and lack of stability of the implant. ${ }^{(2-4)}$ This has motivated research to develop materials and techniques that improve the process of bone remodeling around dental implants and enhance osseointegration. (1) Positive bone stimulation around a functioning osseointegrated dental implant can improve the quality of bone. Increasing amount of bone at the implant site promotes the possibility for implant success. ${ }^{(5)}$

Bisphosphonates have proved their potent inhibition of osteoclasts activity in treatment of many diseases that are characterized by extreme bone resorption, such as osteoporosis, hypercalcemia, and bone metastases. This aroused the interest in their use around dental implants as bone biomodulators. $(1,6)$ Additionally, numerous researches have proposed that bisphosphonates may have a positive impact on the processes of bone formation and remodeling which may consequently promote a considerable reduction in bone turnover and improve the fixation of dental implants. ${ }^{(7-10)}$

Unfortunately, the systemic use of bisphosphonate drugs has caused severe side effects. Consequently, researchers have turned their attention to promote methods of delivering these drugs locally to the concerned site. ${ }^{(11-13)}$ Sodium alendronate gel was manufactured and tested to accelerate osseointegration around dental implants with the concept of positive influence of bone remodeling adjacent to the dental implant, avoiding the undesirable systemic side effects. ${ }^{(1,14)}$

Bone density is the amount of bone tissue defined in a certain volume of bone. Several approaches have been introduced as valid tools for measuring jaw bones and other skeletal bones density such as the spine and femur. ${ }^{(4)}$ Assessment of jaw bone density is considered useful in implant planning. ${ }^{(15)}$ Evaluation of bone quality and osseointegration of dental implants was done by different diagnostic tools such as densitometry of panoramic as well as periapical radiographs, in addition to the Dual Energy X-Ray Absorptiometry (DEXA), computed tomography (CT) and cone-beam computed tomography (CBCT). $(4,16)$ Although, the DEXA is considered the standard gold for calculation of bone mineralization, it cannot provide cross-sectional images which renders it inapplicable for implant dentistry. ${ }^{(17)}$

In the last years, CBCT has been widely employed in oral and maxillofacial imaging due to the proper spatial resolution, gray density range and contrast, in addition to the good pixel/noise ratio. (18) New CBCT machines, providing low radiation exposure, with superior Digital Imaging and Communications in Medicine (DICOM) images that can be easily reformatted by different software programs, can calculate bone density accurately. ${ }^{(5)}$ Numerous researches have approved CBCT after comparing its results with $\mathrm{CT}$, micro-CT as well as histological findings. ${ }^{(18-20)}$ Consequently, CBCT has become the more commonly diagnostic tool for bone density evaluation. ${ }^{(4,17)}$

This study was designed to investigate the impact of topical injection of sodium alendronate gel $1 \%$ on bone density at the posterior region of the mandible around immediately loaded dental implants using CBCT. The hypothesis was that topically applied alendronates would increase bone density around immediately loaded implants.

\section{MATERIALS AND METHODS:}

This study was conducted on 16 patients seeking placement of dental implants in the mandibular posterior region. Patients were received at the outpatient clinic of Oral and Maxillofacial Surgery Department, Faculty of Dentistry, Mansoura 
University, for replacement of a at least one single missed mandibular premolar or molar.

The study followed the Declaration of Helsinki on medical protocol and ethics. It was approved by the Ethical Review Board of Mansoura University. All patients were informed about the nature of the study and signed a written consent with full rights to quit the study at any time.

The predictor variable was local application of alendronate $1 \%$ gel along with placement of immediately loaded dental implants. The outcome variable was measuring bone density around dental implants using CBCT.

\section{MATERIALS}

1. Dental implant: Two pieces dental implants (NEOBIOTECH implant system, Korea), acid etched; screw type.

2. Alendronate gel: Alendronate gel was prepared in Faculty of Pharmacy, Mansoura University. It was derived from FOSAMAX ${ }^{\circledR}$. (fig. 1) (Fosamax $®$ : Trade mark of Merck \& co. Inc., Whitehouse station, N.J., USA, M.O.H Reg. No.: 195/2008)

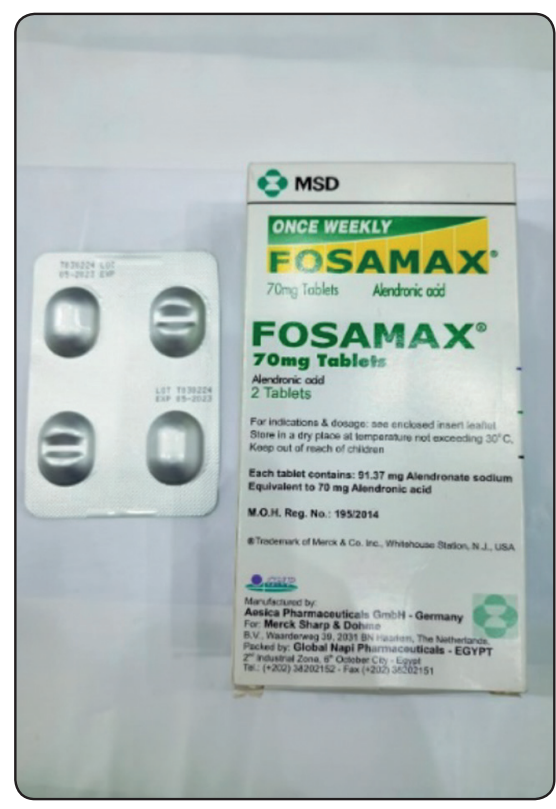

Fig. (1): Fosamax Tablets
Preparation of alendronate gel 1\% (by volume): The gel formula was manufactured as described by Reddy et al. ${ }^{(21)}$ In the required amount of distilled water, the alendronate tablet was dissolved to achieve $1 \%$ concentration. Then a weighed quantity of polyacrylic acid $934 \mathrm{P}(2 \% \mathrm{wt} / \mathrm{wt})$ was added and the mixture was stirred gradually. The polyacrylic acid was allowed to soak for two hours. Triethanolamine (1\%) was added to neutralize the solution and form the gel. Finally, methylparaben $(0.1 \%)$ and propylparaben $(0.05 \%)$ were dissolved in ethanol in the required amounts and added to the gel. The $\mathrm{pH}$ was adjusted to 6.8 .

The alendronate gel was then divided into packs of $0.5 \mathrm{ml}$ each and sterilized using ultraviolet rays under the laminar for 30 minutes. ${ }^{(22,23)}$

3. Cone beam computed tomography: (Veraviewepocs 3D R100, MORITA, Japan)

\section{Patients'selection: ${ }^{(24)}$}

The inclusion criteria included: seeking placement of at least one single dental implant in the posterior mandibular area, age of the patients ranged between 20 to 40 years, sufficient alveolar bone volume at the implant site with minimum $5 \mathrm{~mm}$ width buccolingually, adequate width of keratinized mucosa, non-smokers and patients showing motivation and good oral hygiene.

The exclusion criteria included: presence of local infection, inadequate interocclusal space, bruxism or clenching, current chemotherapy or radiotherapy, alcohol or drug abuse, systemic diseases that may interfere with implants' success, pregnant women, patients with parafunctional habits, patients showing any allergic reaction to Alendronate gel.

\section{Groups Allocation}

Cases were divided randomly into two equal groups by an independent reviewer as follows: 
- Group I (study group): After preparation of the implant sites in 10 cases, alendronate gel $1 \%$ was topically injected inside the prepared drilling sites, then the implants were loaded immediately within 24-72 hours.

- Group II (control group): After preparation of the implant sites in 10 cases, the implants were loaded immediately within 24-72 hours without applying of any bioactive material in the drilling sites.

All patients' data were recorded including; name, gender, age as well as medical and dental histories. Then they went through preoperative phase including clinical examination of recipient site to ensure absence of infection or any signs of inflammation, by examining the oral mucosa covering the edentulous area regarding its color, texture, firmness and thickness. This was followed by $\mathrm{CBCT}$ radiographic examination of recipient site to be implanted, primary impression and fabrication of study model and surgical stent. The diagnostic models and pre-operative CBCT were used for treatment planning of each case. The recipient sites were photographed intra-orally (fig. 2a \& 3a).

Patients were instructed firmly to follow proper oral hygiene. They also received periodontal scaling when needed, to reduce gingival inflammation. Antiseptic mouthwash rinse (Hexitol Chlorhexidine $\mathrm{HCl} 1.25 \%$, by adco company ltd, Alexandria, Egypt) was used for rinsing 30 seconds before the surgery, to decrease the risk of surgical field contamination. Prophylactic antibiotic of one gm amoxicillin + clavulanic acid was prescribed, one tablet the day before and another tablet two hours before surgery. In case of penicillin allergy, Levofloxacin 500mg was prescribed, one tablet the day before and another tablet two hours before surgery.

\section{Surgical Procedure}

After surgical asepsis protocol application, and administration of local anesthesia (articaine 2\% and epinephrine 1:100,000) as an inferior alveolar nerve block in addition to buccal infiltration around the surgical field, a bard parker blade \#15 mounted on a bard parker handle was used for crestal incision of full-thickness mucoperiosteal flap. Using Molt periosteal elevator, the flap was reflected buccally and lingually for exposure of the alveolar ridge at the implant site. A Minnesota retractor was used for flap retraction (fig. 2b).

For all cases, the dental implants' lengths and diameters were pre-planned according to CBCT. The corresponding drills were used in a sequential form without stepping using a contra-angled surgical handpiece mounted on an electric surgical motor with proper cooling system at speed of 8001000 revolution per minute (rpm) and torque 40-50 $\mathrm{N} / \mathrm{Cm}$. Afterwards, the implant site was copiously irrigated with saline (fig. 2c).

- Group I (study group): The alendronate gel was injected in the osteotomy site just before implant placement using a sterile plastic syringe (fig. 2d).

- Group II (control group): The osteotomy site was left empty before implant placement, without application of any bioactive material.

The sealed implant package was carefully opened and the implant was placed with light stable finger pressure into the osteotomy site. The torque wrench was then used to complete implant installation to its final position one $\mathrm{mm}$ beneath the level of the alveolar bone crest. The abutment was installed immediately after implant insertion then the flap was repositioned and sutured using non-resorbable 3/0 silk suture (fig. 2e).

Dental impression was taken using silicone rubber base material, laboratory analogue and impression were made. An acrylic provisional crown was fabricated and delivered within 72 hours of implant placement and was replaced later with porcelain fused to metal crown after complete healing of the surgical site. 


\section{Postoperative phase}

Patients were instructed to apply extra-oral cold packs intermittently every 10 minutes for two hours on the day of surgery, followed by warm saline mouthwashes for the next seven days, avoid hot diet or mouthwash in the first postoperative day, and maintain proper oral hygiene measures. Each participant was maintained on antibiotic (Amoxicillin $875 \mathrm{mg} \&$ Clavulanic acid $125 \mathrm{mg}$ ) (Augmentin ${ }^{\circledR} 1 \mathrm{~g}$ Tablet by Galaxosmithkline co ltd, USA) every 12 hours for 5 days), a non-steroidal anti-inflammatory; Ibuprofen $400 \mathrm{mg}$ : 1 tablet 3 times daily for 4-5 days starting immediately after the operation) (BRUFEN® $400 \mathrm{mg}$ tablets : Abbott Egypt, Cairo, Egypt) and an antiseptic mouthwash (0.12\% Chlorhexidine hydrochloride) (Hexitol ${ }^{\circledR}$ mouthwash: Arab Drug Company (ADCO), Cairo, Egypt) 3 times a day for 7 days, starting the day following the surgery. After seven postoperative days, sutures were removed. The patients were recalled for follow-up after six months and photographed intra-orally (fig. 2f).

\section{Radiographic evaluation of bone density:}

This was done by CBCT with imaging protocol of limited field of view (FOV) and $0.25 \mathrm{~mm}$ voxel size, using the previously mentioned machine.

Bone density around the implants was evaluated pre-operatively and after 6 months of implant insertion and loading. The produced DICOM data from CBCT scanning were transferred to specific image analysis software "On Demand 3D App" (OnDemand3D, Cybermed inc. Korea)

Using the software interactive setting, all scans were viewed. According to the future prosthetic plan, a simulated implant was placed on the reconstructed panoramic images (fig. 3b). The location of the simulated implant was adjusted on the cross-sectional images and the selection of its size allowed for two $\mathrm{mm}$ of bone from the inferior alveolar canal and mental foramen. Using the option of the bone density on the "On Demand" software, the Hounsfield units (HU) were calculated pre-

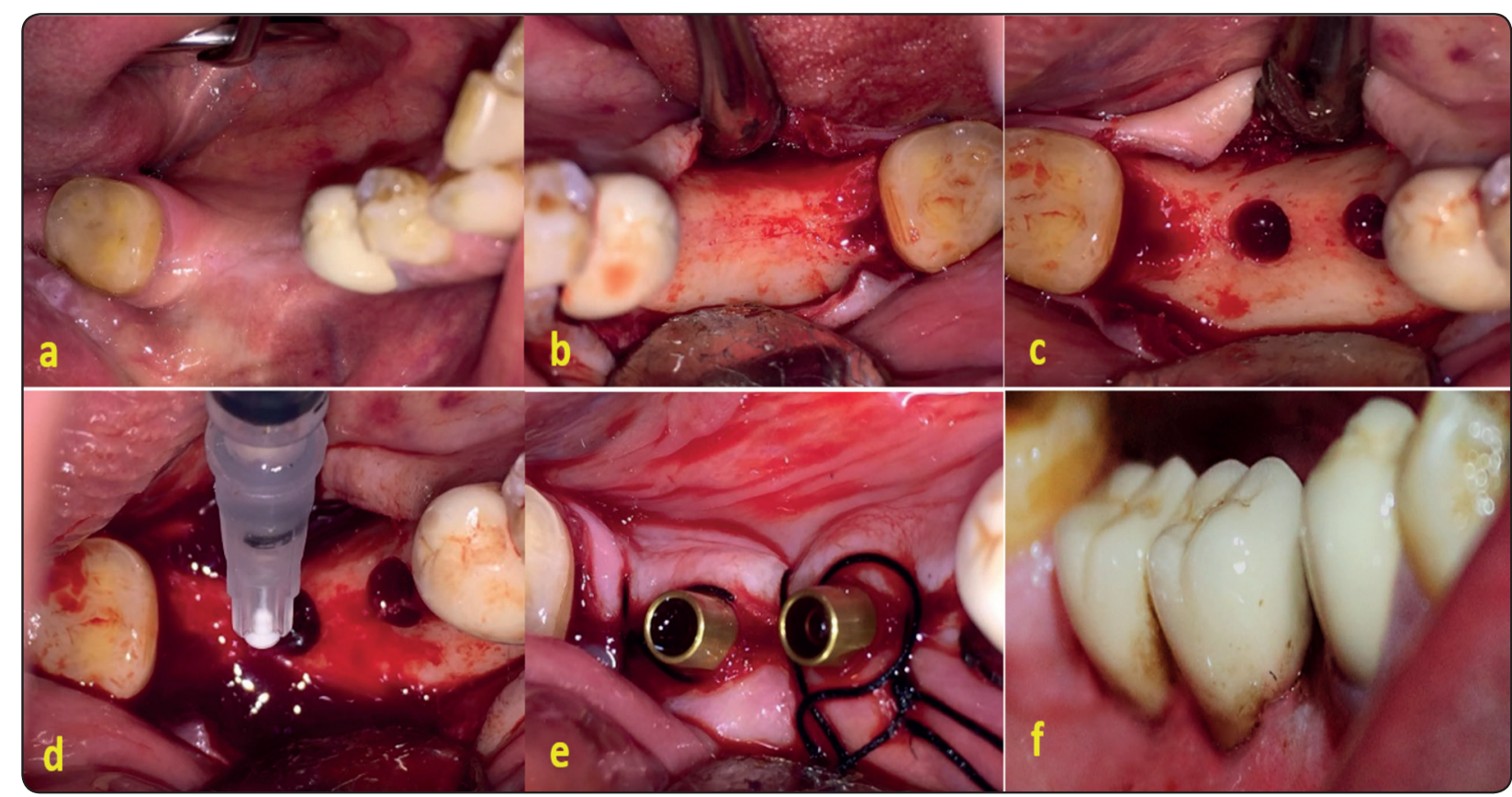

Fig. (2): A photograph showing: a) Pre-operative missed mandibular right first \& second molars. b) Full thickness mucoperiosteal flap reflection \&retraction. c) Osteotomy of the recipient implants sites. d) Local injection of alendronate gel at the posterior implant recipient site.e) Abutments' installation \& flap suturing.f) Final porcelain fused-to-metal restorations of the missed molars, 6-months postoperatively. 


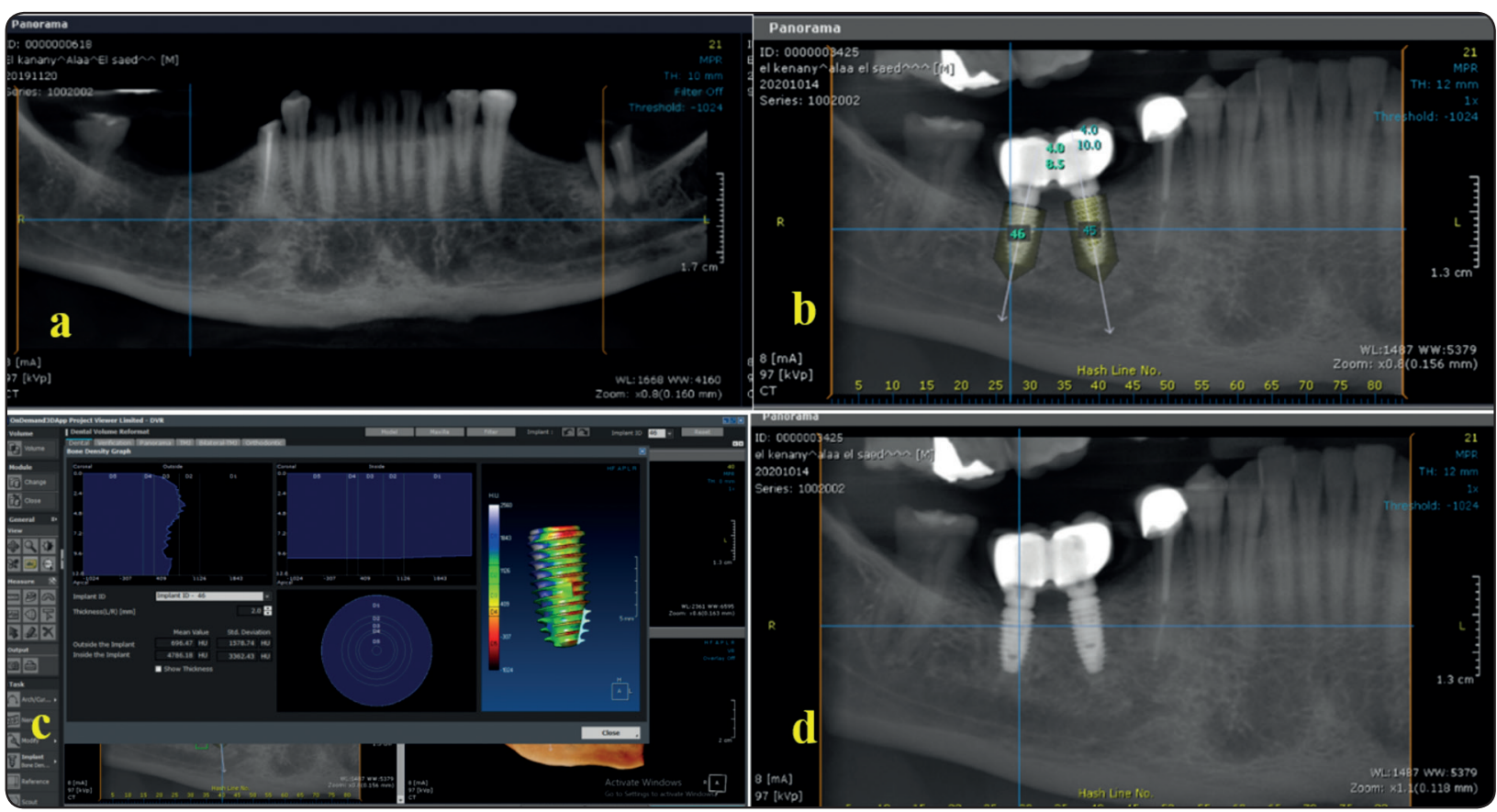

Figure (3): CBCT reconstructed panoramic view showing: a) Pre-operative missed mandibular right first \& second molars. b) Simulated implant placement by the software for measuring bone density. c) Measuring Bone Density using "OnDemand application". d) The placed dental implants, 6 months post-operatively.

operatively at the recipient site of the dental implant and then at two mm around the implant six months after implant insertion and loading (fig. 3c). ${ }^{(4)}$

\section{Statistical Analysis}

The Statistical Package of Social Science (SPSS) program for Windows (Standard version 21) was used for data analysis. Number and percent were used to describe qualitative data. Fischer exact test was used for association between categorical variables (when expected cell count $<5$ ).

For normally distributed data, continuous variables were presented as mean \pm SD (standard deviation). While Student $t$ test was used to compare the two groups, the repeated measured ANOVA test was used to compare means at different durations in the same group and the two paired groups were compared by paired $t$ test. The threshold of significance was fixed at $5 \%$ level. When $\mathrm{p} \leq 0.05$, results were considered significant.

\section{RESULTS}

This study included 16 patients (seven males and nine females) with single or multiple missing mandibular posterior teeth (7 premolars and 13 molars) indicated for implant rehabilitation. The ages of the patients ranged between 23 and 40 years with mean age of 34.35 years (table 1). They were selected from the outpatient clinic of the Oral and Maxillofacial Surgery Department, Faculty of Dentistry, Mansoura University.

A total of twenty implants of Neobiotech system were placed in the healed sites (after more than 6 months of extraction) under local anesthesia using surgical flap technique. Different diameters (4, 4.5 and $5 \mathrm{~mm}$ ) and lengths (8.5, 10 and $11.5 \mathrm{~mm}$ ) were used in this study. The used implant lengths in this study were $10 \mathrm{~mm}$ in twelve patients, $11.5 \mathrm{~mm}$ in seven patients and $8.5 \mathrm{~mm}$ in one patient. Implant diameters in this study ranged from $4 \mathrm{~mm}$ to $5 \mathrm{~mm}$. The used implant diameters were $4 \mathrm{~mm}$ in eight patients, $4.5 \mathrm{~mm}$ in four patients and $5 \mathrm{~mm}$ in eight patients. 
All patients received acrylic functional provisional restorations followed by porcelain fused to metal crowns. They were followed up radiographically for six months (fig. 3d).

\section{Radiographic evaluation of bone density:}

Comparing bone density at follow-up intervals in the study group:

- Pre-operatively, the maximum and minimum recorded bone density values were 797.4 HU and $363.57 \mathrm{HU}$, with mean value $557.30 \pm 132.06$ HU. After six months, the maximum and minimum recorded bone density values were 1213.7 HU and 589 HU respectively, with mean value $852.03 \pm 176.43 \mathrm{HU}$. This indicates high significant difference in bone density values at the follow-up interval within the study group ( $\mathrm{P} \leq 0.001)$ (table 2 \& fig. 4).

$\leftarrow$ Comparing bone density at follow-up intervals in the control group:
- Pre-operatively, the maximum and minimum recorded bone density values were $720.34 \mathrm{HU}$ and $357.70 \mathrm{HU}$, with mean value $567.62 \pm 110.72$ HU. After six months, the maximum and minimum recorded bone density values were $832 \mathrm{HU}$ and $443.66 \mathrm{HU}$ respectively, with mean value $670.11 \pm 117.71 \mathrm{HU}$. This indicates high significant difference in bone density values at the follow-up interval within the control group $(\mathrm{P} \leq 0.001)$ (table 3 \& fig. 5).

$\leftarrow$ Comparing bone density between both groups after $6^{\text {th }}$ months after implant insertion and loading: Immediately before implant placement, the mean peri-implant bone density value was $557.30 \pm 132.06 \mathrm{HU}$ for study group and $567.62 \pm 110.72 \mathrm{HU}$ for control group. This indicates statistically significant difference between both groups after six months $(\mathrm{P}=0.014)$ (table 4 \& fig. 6).

TABLE (1): Sociodemographic data in the studied groups:

\begin{tabular}{|l|c|c|c|c|}
\hline & Group (I) (n=10) & Group (II) (n=10) & Test of significance & p value \\
\hline Age (years) & & & & \\
Mean \pm SD & $35.5 \pm 5.54$ & $33.2 \pm 5.39$ & $\mathrm{t}=0.941$ & 0.359 \\
Min-Max & $23-40$ & $24-40$ & & \\
\hline Gender & $5(50.0 \%)$ & $4(40.0 \%)$ & FET & 1.0 \\
Male & $5(50.0 \%)$ & $6(60.0 \%)$ & & \\
Female &
\end{tabular}

t: student t- test, FET: Fischer exact test

TABLE (2): Comparison of bone density CBCT (HU unit) pre-operatively and 6-months post-operatively within group I

\begin{tabular}{|c|c|c|c|}
\hline \multirow{2}{*}{$\begin{array}{c}\text { Bone Density CBCT } \\
\text { (HU unit) }\end{array}$} & Pre-operative & After 6 Months & F (p value) \\
\cline { 2 - 4 } & $557.30 \pm 132.06363 .57-797.40$ & $852.03 \pm 176.43589-1213.70$ & $\mathrm{~F}=218 \mathrm{P} \leq 0.001^{* *}$ \\
\hline Mean \pm SD Min-Max & & \multicolumn{3}{|c|}{ Group (I) (n=10) } \\
\hline
\end{tabular}

t: paired t test

**Highly significant $p \leq 0.001$ 
TABLE (3): Comparison of bone density CBCT (HU unit) pre-operatively and 6-months post-operatively within group II

\begin{tabular}{|l|c|c|c|}
\hline \multirow{2}{*}{$\begin{array}{c}\text { Bone Density CBCT (HU } \\
\text { unit) }\end{array}$} & \multicolumn{2}{|c|}{ Group (II) (n=10) } & \multirow{2}{t}{$\begin{array}{c}\mathbf{1} \\
\text { (p value) }\end{array}$} \\
\cline { 2 - 3 } & Pre-operative & After 6 Months & \\
\hline Mean \pm SD & $567.62 \pm 110.72$ & $670.11 \pm 117.71$ & $t=26.23$ \\
Min-Max & $357.70-720.34$ & $443.66-832$ & $P \leq 0.001 * *$ \\
\hline
\end{tabular}

t: paired t test

**Highly significant $p \leq 0.001$

Table (4): Bone Density measured using CBCT (HU unit) in both studied groups pre-operatively and 6-months post-operatively.

\begin{tabular}{|l|c|c|c|c|}
\hline $\begin{array}{c}\text { Bone Density measured } \\
\text { using CBCT (HU unit) }\end{array}$ & Group (I) (n=10) & Group (II) (n=10) & $\begin{array}{c}\text { Test of } \\
\text { significance }\end{array}$ & p value \\
\hline Pre-operative & $557.30 \pm 132.06$ & $567.62 \pm 110.72$ & $\mathrm{t}=0.189$ & 0.852 \\
Mean \pm SD & $363.57-797.40$ & $357.70-720.34$ & & \\
Min-Max & $852.03 \pm 176.43$ & $670.11 \pm 117.71$ & $\mathrm{t}=2.71$ & $0.014^{*}$ \\
\hline 6 Months & $589-1213.70$ & $443.66-832$ & & \\
Mean \pm SD & Min-Max &
\end{tabular}

\section{*: Statistically significant at $p \leq 0.05$}

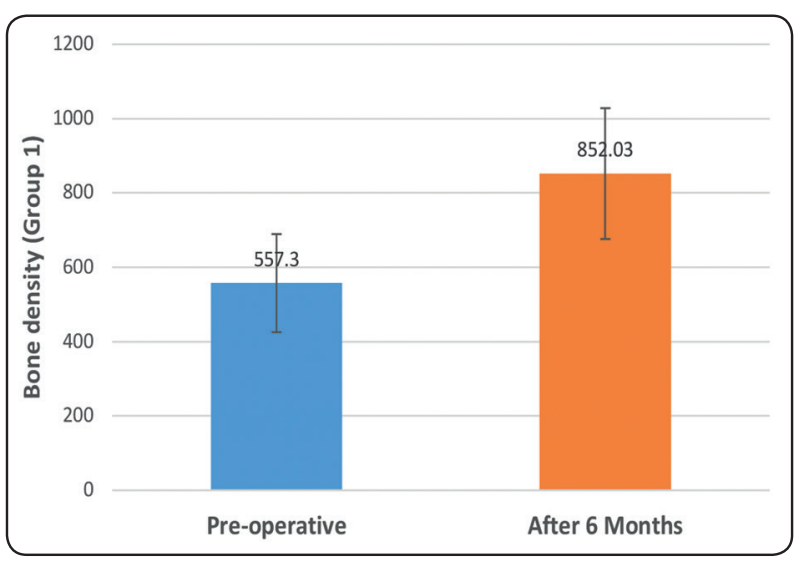

Fig. (4): Mean bone density pre-operatively and 6-months postoperatively within group I.

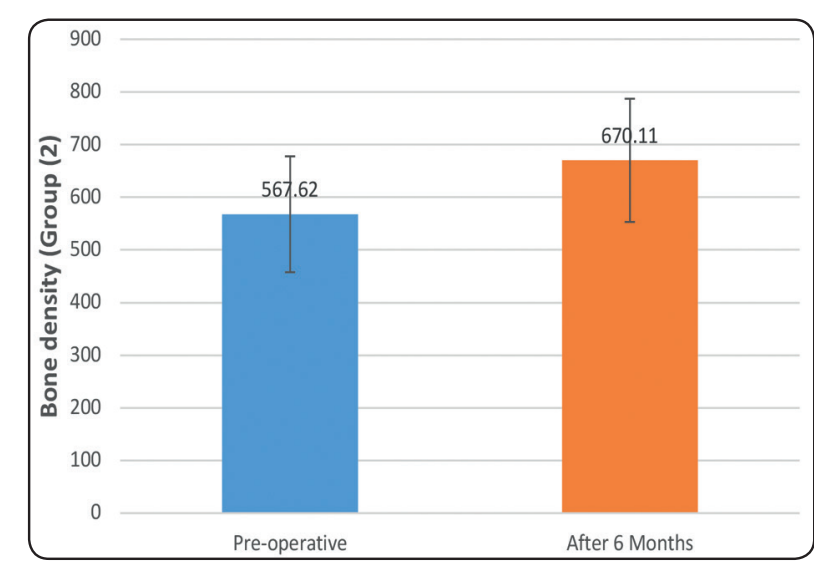

Fig. (5): Mean bone density pre-operatively and 6-months postoperatively within group II. 


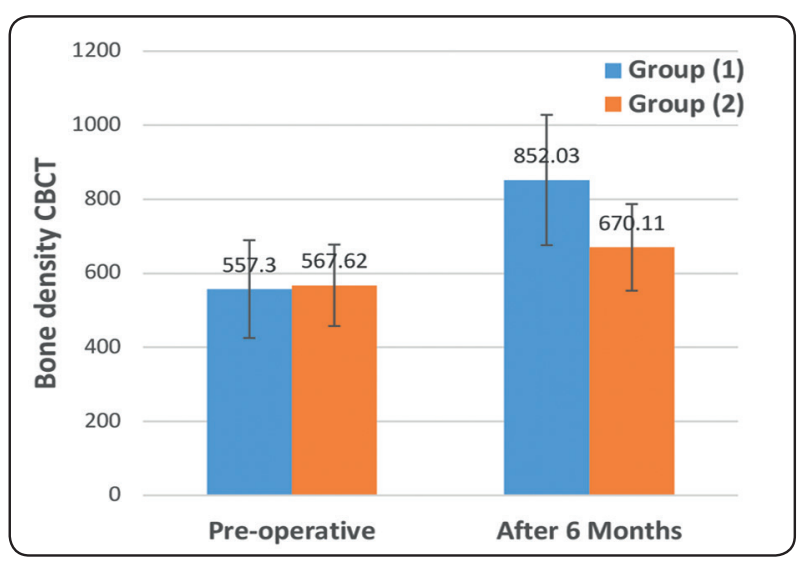

Fig. (6): Mean Bone Density among studied groups preoperatively and 6-months post-operatively.

\section{DISCUSSION}

Researchers have been striving to figure out the best way of administering bisphosphonate in particular focusing on systemic administration or local application of the bisphosphonate to implants. ${ }^{(25)}$ In this study, alendronate was topically applied in a gel form in the osteotomy sites of dental implants, to ensure the availability of alendronate gel at the recipient implant site, since it adheres to the nearest bone surface and remains there for a long time with the bone surface acting as a store for repeated release of the material where it is most needed. The gel presented adequate viscosity for application by means of syringes, and did not favour the growth of microorganisms after being sterilized. On the contrary, systemic administration was not preferred in this study, since bones are low-perfusion organs. Accordingly, it is challenging for any drug diluted in blood stream to reach the required recipient implant site for sufficient time or concentration to prove efficacy. ${ }^{(25-27)}$

In the present study, CBCT was selected for measuring the bone density since it is accurate with lower radiation exposure when compared with CT. This was in accordance with Cassetta et al (28) who compared the bone density values (gray density values) produced by $\mathrm{CBCT}$ and conventional $\mathrm{CT}$ by scanning twenty dry mandibles. They concluded that $\mathrm{CBCT}$ is a useful substitute for CT, meanwhile, the more accurate definition of bone density with CBCT requires application of a conversion ratio to the voxel value. This agrees with a study by Katsumata et al. ${ }^{(29)}$, who calculated a wide range of $-1500 \mathrm{HU}$ to over $+3000 \mathrm{HU}$ on CBCT for different bone types. However, after a correction has been applied to grey levels with the CBCT, they recorded HU values that were much similar to those in medical CT device than to the original grey levels of the CBCT scanners.

Parsa et al ${ }^{(30)}$ have assessed the feasibility of converting CBCT gray values to actual density measurements and demonstrated a high correlation between HU derived from multi slice spiral computed tomography (MSCT) and CBCT voxel gray values, validating the potential of CBCT in bone density assessment in dental implant sites.

Patients suffering from any uncontrolled systemic diseases or conditions, were excluded from this study. This was following Bornstein et. al ${ }^{(31)}$, who studied the risk of implant failure in patients suffering systemic diseases with or without systemic medications. They stated that there is low level of evidence that indicates the absolute and relative contraindications for implant therapy due to systemic diseases. Thus, patients suffering systemic diseases may diminish the success rates of dental implants. ${ }^{(32,33)}$

Additionally, this study excluded patients suffering from bruxism, heavy smokers, patients receiving chemotherapy or radiotherapy and immunosuppressed patients. This was following a study performed by Van Steenberghe et al ${ }^{(34)}$ in 2002, who pointed out that general/local factors such as heavy smoking, chemotherapy and radiotherapy affect early implant outcome. This comes in accordance with many recent studies that correlated the above mentioned local and systemic factors to higher rates of implants loss. ${ }^{(35,36)}$ 
In the current study, all patients were instructed to adhere to strict oral hygiene preoperatively and during the postoperative follow-up. This agrees with a review performed by Esposito et al ${ }^{(37)}$ suggested the use of a single dose of $2 \mathrm{gm}$ prophylactic amoxicillin before implant surgery to reduce the chance of bacterial proliferation and dissemination. It is worth mentioning that the American Heart Association has suggested prophylactic antibiotic coverage before complex surgical procedure including implant placement. Amoxicillin and penicillin were recommended as the first line of treatment due to their superior absorption and prolonged serum levels. ${ }^{(38,39)}$

In the present study, the bone density evaluated preoperatively recorded the lowest value during the follow up. This could be referred to the selection of cases that have undergone tooth extraction for more than six months. This long-standing effect of missing posterior teeth leads to absence of functional dynamic alveolar bone stimulation. ${ }^{(40)}$

Both control and study groups showed significant increase in mean bone density towards the sixth month post-operatively. These results were in agreement with Youssef et al. ${ }^{(24)}$ study that estimated bone density by $\mathrm{CBCT}$ in ten tapered implants inserted in posterior mandibular edentulous space. They stated that the mean of the immediate postoperative bone density value was $827.96 \pm 206.85$ $\mathrm{HU}$, then increased to $1018.0 \pm 149.79 \mathrm{HU}$ on the sixth month, indicating a statistically significant increase. This can be explained by the physiologic healing process of the bone around implants.

Furthermore, a study conducted by Al-Sudani in $2014^{\left({ }^{41)}\right.}$ used CT scan for measuring of bone density around twenty implants in the posterior region of both maxilla and mandible. The mean bone density following implant placement immediately was 552.28 HU and showed statistically significant increase to $761.33 \mathrm{HU}$ after six months, which correlates with the findings of the present study.
After 6-months of implant placement and loading, there was statistically significant difference ( $\mathrm{p}=0.014)$ in mean bone density between both groups. These results are in line with Stadelmann et al (42) who conducted a study on osteoporotic sheep model and confirmed that implants with locally delivered bisphosphonates have shown increased periprosthetic bone density. Additionally, in agreement with the present study, Meraw et al (43) stated that the local application of alendronate around dental implants in dog mandibles has increased bone density. They did not directly apply the bisphosphonate into the implant recipient site; instead, the implant was soaked in the solution.

On other hand, the findings of this study did not agree with Denissen et al study in $2000{ }^{(44)}$, as they did not report any advantages or disadvantages associated with the locally delivered bisphosphonate on the surface of porous hydroxy apatite implants. In addition to another experimental study and analysis conducted by Guimaraes et al ${ }^{(1)}$ that reported harmful effect of local application of sodium alendronate gel on osseointegration of titanium implants installed in rabbit tibias. Moreover, they recorded a visibly negative influence on bone remodeling around the implants inserted.

\section{CONCLUSION}

Within the limitation of this study, it was concluded that injection of sodium alendronate gel $1 \%$ inside the osteotomy sites of immediate loaded implants have increased bone density around dental implants, which consequently can increase implant success rate.

\section{RECOMMENDATIONS}

Further studies with longer evaluation period and larger sample size are required to get more affirmative and conclusive results about the topical effect of alendronate on the quantity and quality of bone healing around dental implants. 


\section{ABBREVIATIONS}

CBCT: cone beam computerized tomography.

CT: computed tomography.

DEXA: Dual Energy X-Ray Absorptiometry.

HU: Hounsfield unit.

\section{ACKNOWLEDGEMENT}

Special thanks to Prof. Dr. Farid A. Badria, Professor of Pharmacognosy, Head of Liver Research Lab., Head of Drug Discovery Unit, Faculty of Pharmacy, Mansoura University, Egypt, for his invaluable aid in preparation of the alendronate gel.

\section{Authors' contributions}

Both authors have contributed in: concept/design, data analysis, critical revision, final approval. They read and approved the final manuscript.

\section{Funding Sources}

None.

\section{DECLARATIONS}

\section{Ethics approval and consent to participate}

The study protocol was approved by the Ethical Committee of the Faculty of Dentistry, Mansoura University, Egypt.

\section{Consent for publication}

Not applicable.

\section{Competing interests}

The authors declare no potential conflicts of interest with respect to the authorship and/or publication of this article.

\section{REFERENCES}

1. Guimaraes MB, Bueno RS, Blaya MB, Shinkai RS, Marques LM. Influence of the local application of sodium alendronate gel on osseointegration of titanium implants. Int J Oral Max Surg. 2015;44(11):1423-9.
2. Roy M, Loutan L, Garavaglia G, Hashim D. Removal of Osseo integrated dental implants: a systematic review of explanation techniques. Clin Oral Invest. 2020 ;24(1):4760.

3. Vidyasagar L, Apse P. Dental implant design and biological effects on bone-implant interface. Stomatologija 2004; 6: 51-4.

4. Gulsahi A. Bone quality assessment for dental implants. Rijeka: InTech 2011: 437-52.

5. Alghamdi, H.S. Methods to Improve Osseointegration of Dental Implants in Low Quality (Type-IV) Bone: An Overview. J. Funct. Biomater. 2018,9,7. https://doi. org/10.3390/jfb9010007

6. Mundy GR, Yoneda T. Bisphosphonates as anticancer drugs. N Engl J Med 1998;339: 398-400.

7. Yamashita J, Sawa N, Sawa Y, Miyazono S. Effect of bisphosphonates on healing of tooth extraction wounds in infectious osteomyelitis of the jaw. Bone. 2021; 143:115611.

8. Sher J, Miller C, Sharma D. Effect of Bisphosphonates on the Osteogenic Activity of Osteoprogenitor Cells Cultured on Titanium Surfaces. Int J Oral Maxillofac Implants. $2020 ; 35$.

9. Demircan S, İşler SC. Histopathological Examination of the Effects of Local and Systemic Bisphosphonate Usage in Bone Graft Applications on Bone Healing. Journal of Maxillofacial and Oral Surgery. 2021;20(1):144-8.

10. Kim JY, Choi H, Park JH, Jung HD, Jung YS. Effects of anti-resorptive drugs on implant survival and periimplantitis in patients with existing osseointegrated dental implants: a retrospective cohort study. Osteoporosis International. 2020;31(9):1749-58.

11. Golden A. Bisphosphonates in improving the osseointegration of dental implants. Duluth Journal of Advanced Writing. 2020;15;1: 33-9.

12. Tsikouris TP. The role of bisphosphonates in success and survival of dental implants-effects in osseointegration. Journal of Research and Practice on the Musculoskeletal System. JRPMS.December 2020;4:125-129.

13. Li D, Zhou J, Zhang M, Ma Y, Yang Y, Han X, Wang X. Long-term delivery of alendronate through an injectable tetra-PEG hydrogel to promote osteoporosis therapy. Biomater Sci. 2020;8(11):3138-46. 
14. Hotieba AA, Sharara AA, Osman SM. The Effect of Sodium Alendronate Gel on Osseointegration of Submerged Dental Implants. Alexandria Dental Journal. 2020;45(1):1-6.

15. Gulsahi, A., Ozden, S., Paksoy, C.S., Kucuk, O., Cebeci, A.R.I, Genc Y. Assessment of Bone Mineral Density in The Jaws and Its Relationship to radiomorphometric Indices. Dentomaxillofac Radiol,2010;39;284-89.

16. Soylu, E., Coşgunarslan, A., Çelebi, S. Soydan, D., Demirbaş, A.E. and Demir, O. Fractal analysis as a useful predictor for determining osseointegration of dental implant? A retrospective study. Int J Implant Dent 2021;7: $14 \quad$ https://doi.org/10.1186/s40729-02100296-0

17. Jeong KI, Kim SG, Oh JS, Jeong MA. Consideration of various bone quality evaluation methods. Implant Dent. 2013;22(1):55-9.

18. Arisan V, Karabuda ZC, Avsever H, Özdemir T. Conventional multi-slice computed tomography (CT) and cone-beam CT (CBCT) for computer assisted implant placement. Part I: relationship of radiographic gray density and implant stability. Clin Implant Dent Relat Res 2013; 15: 893-906.

19. Suttapreyasri S., Suapear P., Leepong N. The Accuracy of Cone-Beam Computed Tomography for Evaluating Bone Density and Cortical Bone Thickness at the Implant Site: Micro-Computed Tomography and Histologic Analysis. J. Craniofac. Surg. 2018;29: 2026-31 doi: 10.1097/ SCS.0000000000004672

20. Sheikhi M, Karami M, Abbasi S, Moaddabi A, Soltani P. Applicability of cone beam computed tomography gray values for estimation of primary stability of dental implants. Brazilian Dent. Sci. 2021;24(1):8-.

21. Reddy GT, Kumar TM \& Veena KM. Formulation and evaluation of alendronate sodium gel for the treatment of bone resorptive lesions in periodontitis. Drug Deliv. 2005;12: 217-22.

22. Rafael D, Andrade F, Martinez-Trucharte F, Basas J, SerasFranzoso J, Palau M, Gomis X, Pérez-Burgos M, Blanco A, López-Fernández A, Vélez R. Sterilization procedure for temperature-sensitive hydrogels loaded with silver nanoparticles for clinical applications. Nanomaterials. 2019;9(3):380.

23. Huebsch N, Gilbert M, Healy KE. Analysis of sterilization protocols for peptide-modified hydrogels. J Biomed Mater Res. 2005;74(1):440-7.
24. Youssef M, Shaaban AM, Eldibany R. The correlation between bone density and implant stability. Alexandria Dental Journal. 2015;40(1):15-21.

25. Wermelin K, Tengvall P, Aspenberg P. Surface-bound bisphosphonates enhance screw fixation in ratsincreasing effect up to 8 weeks after insertion. Acta Orthop.2007;78:385-92.

26. McKenzie K, Bobyn JD, Roberts J, Karabasz D, Tanzer M. Bisphosphonate remains highly localized after elution from porous implants. Clin Orthop Relat Res. 2011; 469:514-22.

27. Russell R, Watts N, Ebetino F, Rogers M. Mechanisms of action of bisphosphonates: similarities and differences and their potential influence on clinical efficacy. Osteoporos Int.2008; 19:733-59.

28. Cassetta M, Stefanelli LV, Pacifici A, Pacifici L, Barbato E. How accurate is CBCT in measuring bone density? A comparative CBCT-CT in vitro study. Clin Implant Dent Relat Res 2014; 16: 471-8.

29. Katsumata, A., Hirukawa, A., Okumura, S., Naitoh, M., Fujishita, M., Ariji, E., Langlais, R.P. Effects of image artifacts on gray-value density in limited-volume-conebeam Computerized tomography. Oral Surg Oral Med Oral Pathol Oral Radiol Endod:2007;104: 829-36.

30. Parsa A, Ibrahim N, Hassan B, van der Stelt P, Wismeijer D. Bone quality evaluation at dental implant site using multislice CT, micro-CT, and cone beam CT. Clin Oral Implants Res. 2015;26(1): e1-7.

31. Bornstein MM, Cionca N, Mombelli A. Systemic conditions and treatments as risks for implant therapy. Int $\mathrm{J}$ Oral Maxillofac Implants. 2009; 24: 12-27.

32. Block MS, Christensen BJ, Mercante DE, Chapple AG. What Factors Are Associated with Implant Failure? J Oral Maxillofac Surg. 2021;79(1):91-7.

33. Halpern LR, Adams DR. Medically Complex Dental Implant Patients: Controversies About Systemic Disease and Dental Implant Success/Survival. Dental Clinics. 2021;65(1):1-9.

34. Van Steenberghe D, Jacobs R, Desnyder M, Maffei G, Quirynen M. The relative impact of local and endogenous patient-related factors on implant failure up to the abutment stage. Clin Oral Implants Res. 2002;13(6):617-22.

35. Coelho TD, de Azevedo RA, Maia WW, Dos Santos JN, Cury PR. Evaluation of the Association of Early Implant 
Failure with Local, Environmental, and Systemic Factors: A Retrospective Study. J Oral Maxillofac Surg. 2021 Jan 29.

36. Chrcanovic BR, Albrektsson T, Wennerberg A. Smoking and dental implants: a systematic review and metaanalysisJ Dent. 2015;43(5):487-98

37. Esposito M, Grusovin MG, Worthington HV. Interventions for replacing missing teeth: antibiotics at dental implant placement to prevent complications. Cochrane Database Syst. Rev.2013(7).

38. Surapaneni H, Yalamanchili PS, Basha MH, Potluri S, Elisetti N, Kumar MK. Antibiotics in dental implants: A review of literature. J Pharm Bioallied Sci. 2016;8: S28.

39. Dajani AS, Taubert KA, Wilson W, Bolger AF, Bayer A, Ferrieri P, Ferrieri, P., Gewitz, M.H., Shulman, S.T., Nouri, S., Newburger, J.W. and Hutto, C. Prevention of bacterial endocarditis. Recommendations by the American Heart Association. JAMA. 1997; 277:1794-801.
40. Ikar M, Grobecker-Karl T, Karl M, Steiner C. Mechanical stress during implant surgery and its effects on marginal bone: a literature review. 2020; 51 (2); 142-150

41. Al-Sudani RJ. Assessment of bone density after six months from dental implants placement using Computed Tomography. J Bagh Coll Dentistry 2014; 26: 126-8.

42. Stadelmann VA, Terrier A, Gauthier O, Bouler J-M, Pioletti DP. Implants delivering bisphosphonate locally increase periprosthetic bone density in an osteoporotic sheep model. A pilot study. Eur Cell Mater. 2008; 16:10-6.

43. Meraw SJ,Reeve CM,Wollan PC.Use of alendronate inperiimplant defect regeneration. J Periodontol.1999;70:151-8

44. Denissen H, Montanari C, Martinetti R, Van Lingen A, Vanden Hooff A. Alveolar bone response to submerged bisphosphonate-complexed hydroxyapatite implants. J Periodontol. 2000; 71:279-86. 